Supplement of Saf. Nucl. Waste Disposal, 1, 251-253, 2021

https://doi.org/10.5194/sand-1-251-2021-supplement

(c) Author(s) 2021. CC BY 4.0 License.

Supplement of

\title{
Knowledge Management in the Federal Company for Radioactive Waste Disposal (BGE)
}

\section{Gunnar Hoefer et al.}

Correspondence to: Gunnar Hoefer (gunnar.hoefer@bge.de)

The copyright of individual parts of the supplement might differ from the article licence. 
KNOWLEDGE MANAGEMENT IN THE FEDERAL COMPANY FOR RADIOACTIVE WASTE DISPOSAL (BGE)

GunNar Hoefer, Sebastian Wanka, Peter L. Wellmann Berlin, $10^{\text {th }}$ November 2021 
KNOWLEDGE MANAGEMENT IN THE BGE

Safie

Interdisciplinary
research symmosium
on the safet of nuclear
disposal practices

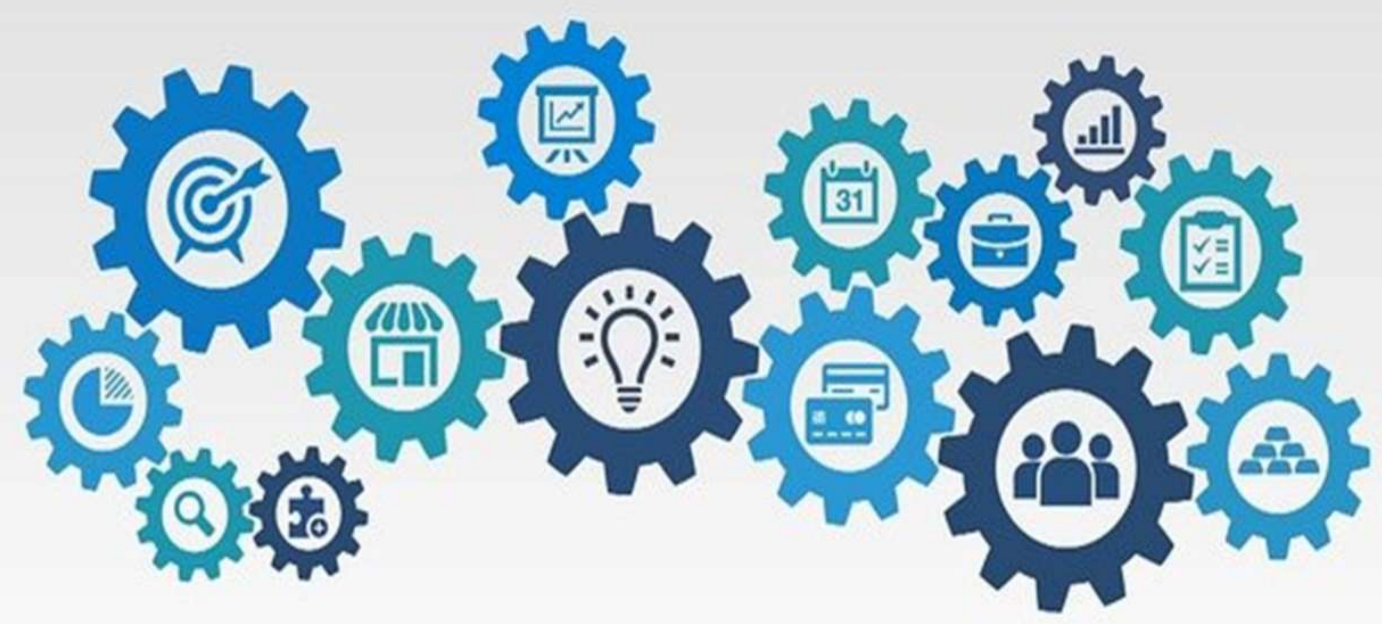


KNOWLEDGE MANAGEMENT IN THE BGE

- WHY?

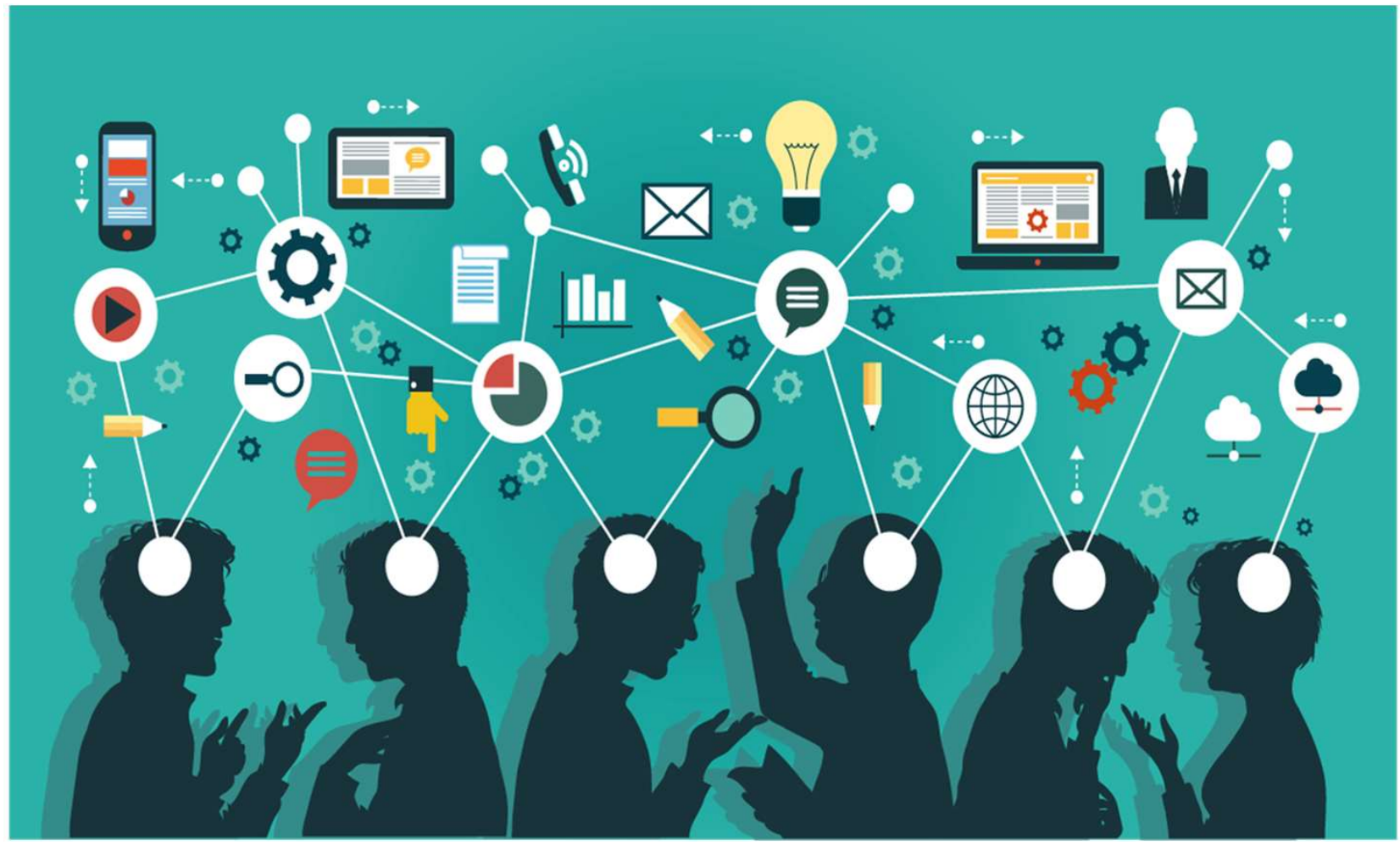




\section{KNOWLEDGE MANAGEMENT IN THE BGE}

\section{- WHY?}

- Intergenerational duration of our projects

- Acute threat of loss of Know-how

- Generation change

- Personnel turnover

○ Job change (internal/external)

- Skills shortage

- Decline in national mining activities

- Exit from nuclear technology 


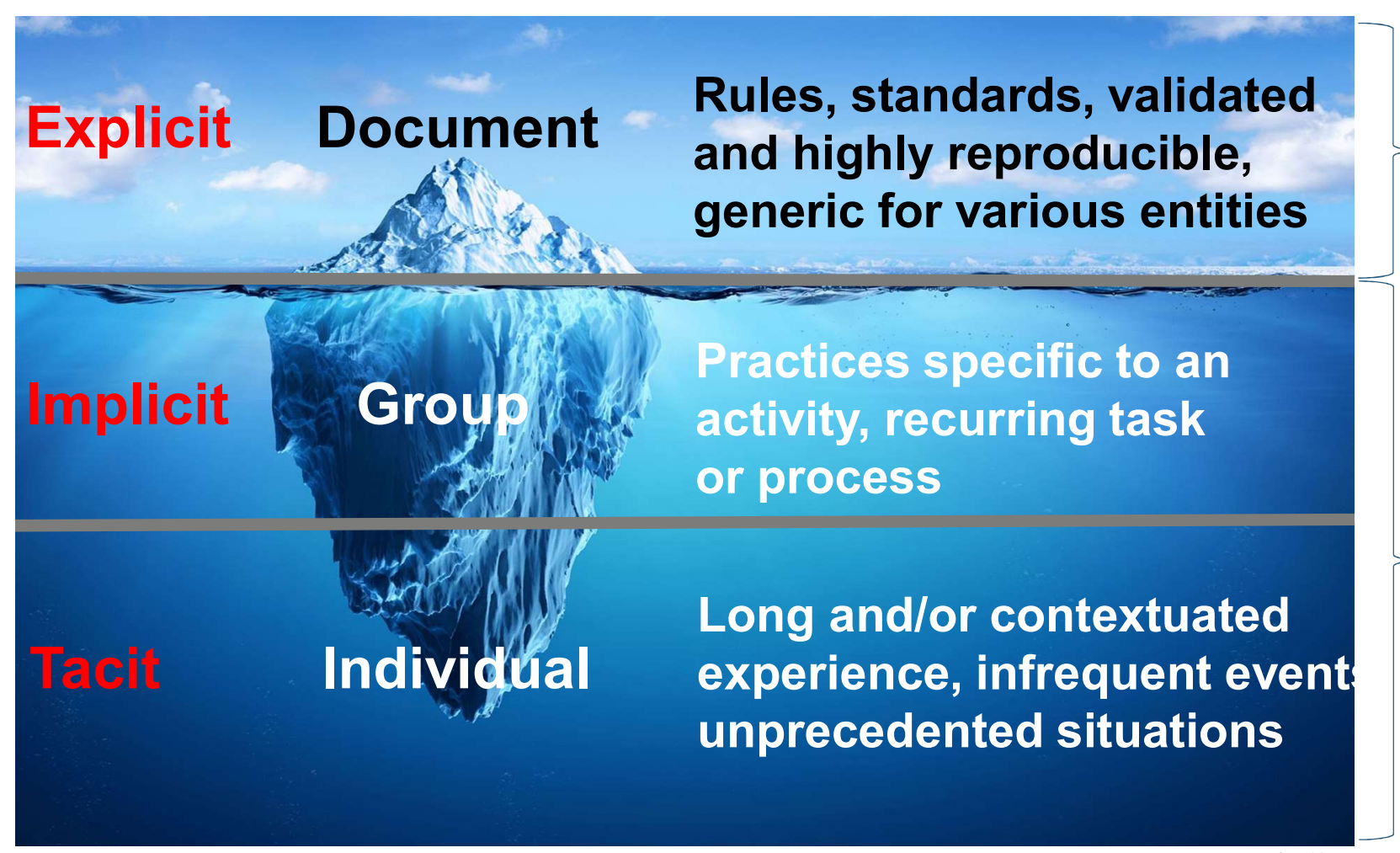

Retrieveable / accessable

„Know how" - individual or group/team related 


\section{KNOWLEDGE MANAGEMENT IN THE BGE}

\section{- CAPTURE OF EXPLICIT KNOWLEDGE}
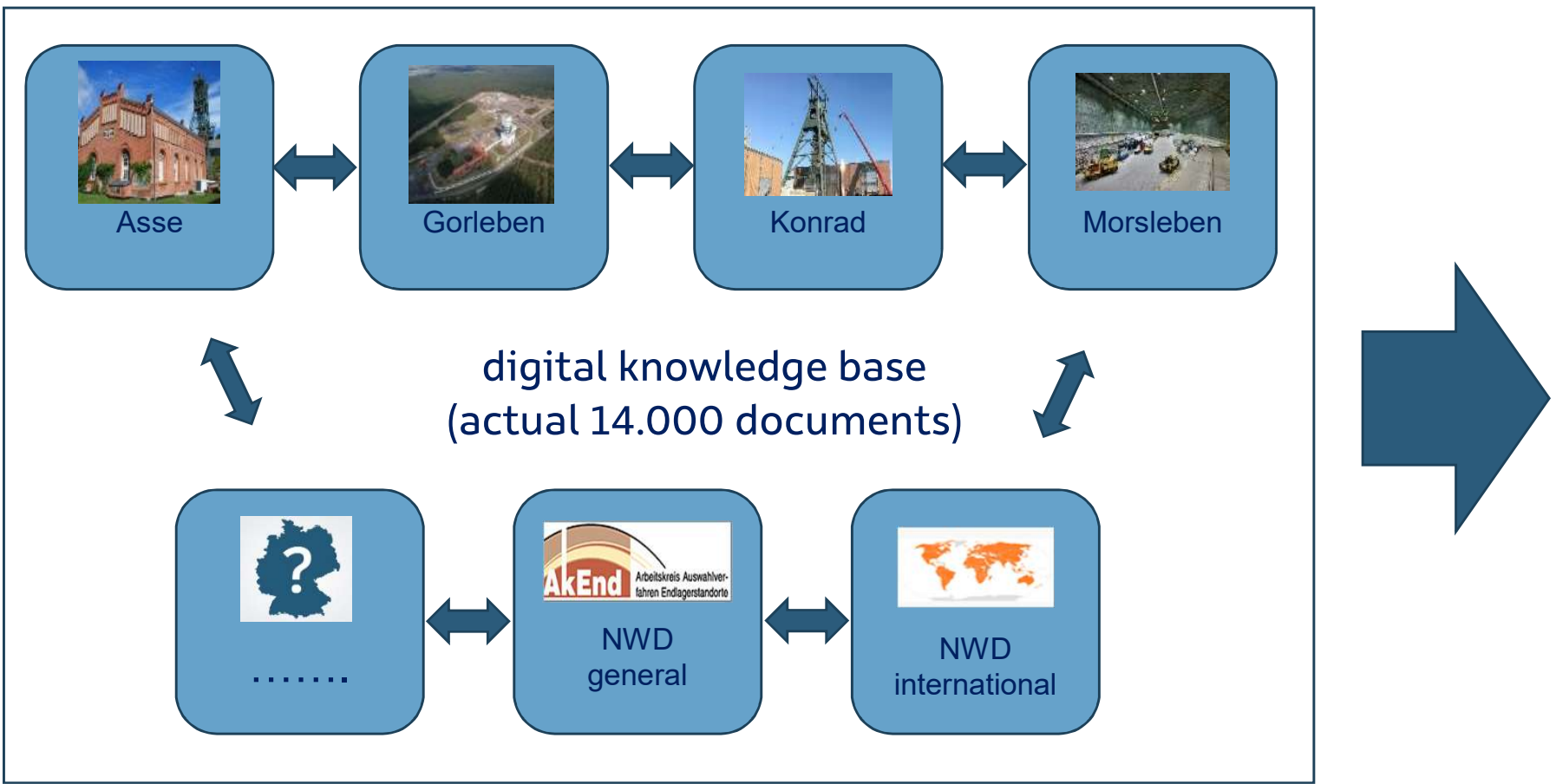

- Collect, secure and distribute

- Inventory of existing knowledge

- Basis for decision/orientation 


\section{KNOWLEDGE MANAGEMENT IN THE BGE}

\section{- EXPLICIT KNOWLEDGE}

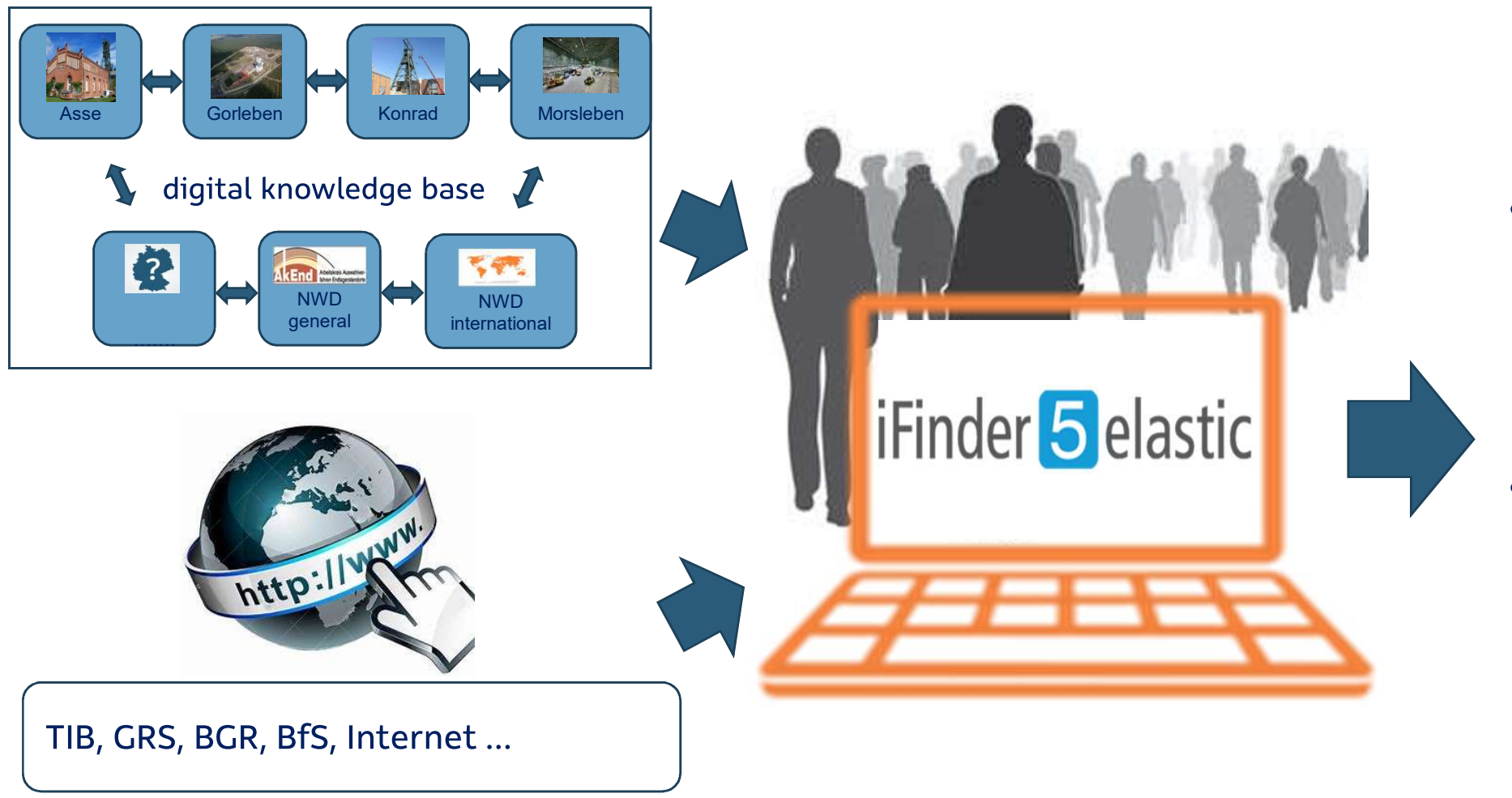

- Content indexing and provision of workrelevant information by means of software

- Connection of external data sources for information/literature procurement 
KNOWLEDGE MANAGEMENT IN THE BGE

\section{- EXPLICIT KNOWLEDGE / DISTRIBUTION}

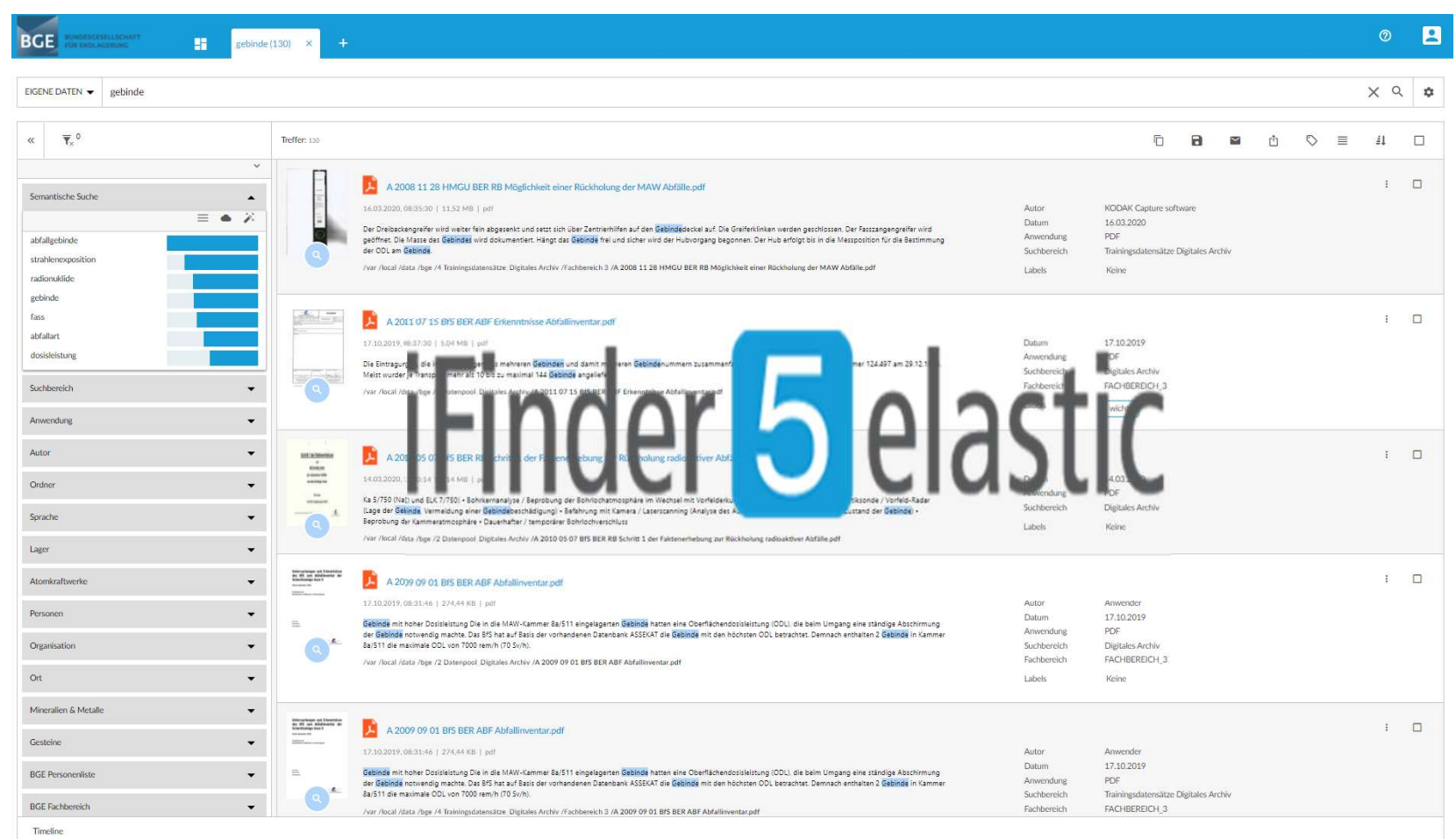

BCE Bundescesellschaft

FÜR ENDLAGERUNG

IntraFind $\mathrm{GmbH}$ München

https://intrafind.com/de

Status:

- 05/2021-Implementation

- 07/2021 - Testphase

- 10/2021 - Launch 


\section{KNOWLEDGE MANAGEMENT IN THE BGE}

\section{- EXPLICIT KNOWLEDGE / DISTRIBUTION}

- Who can I ask inside and outside the organisation?

- Quick overview and orientation through interactive knowledge maps

- New in the company or to the topic?
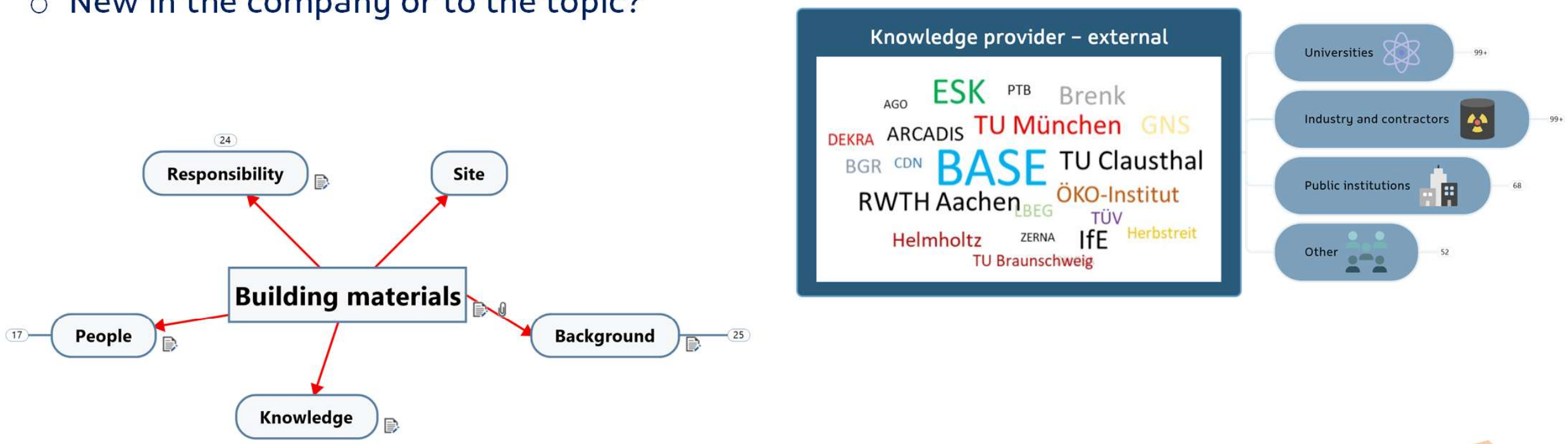


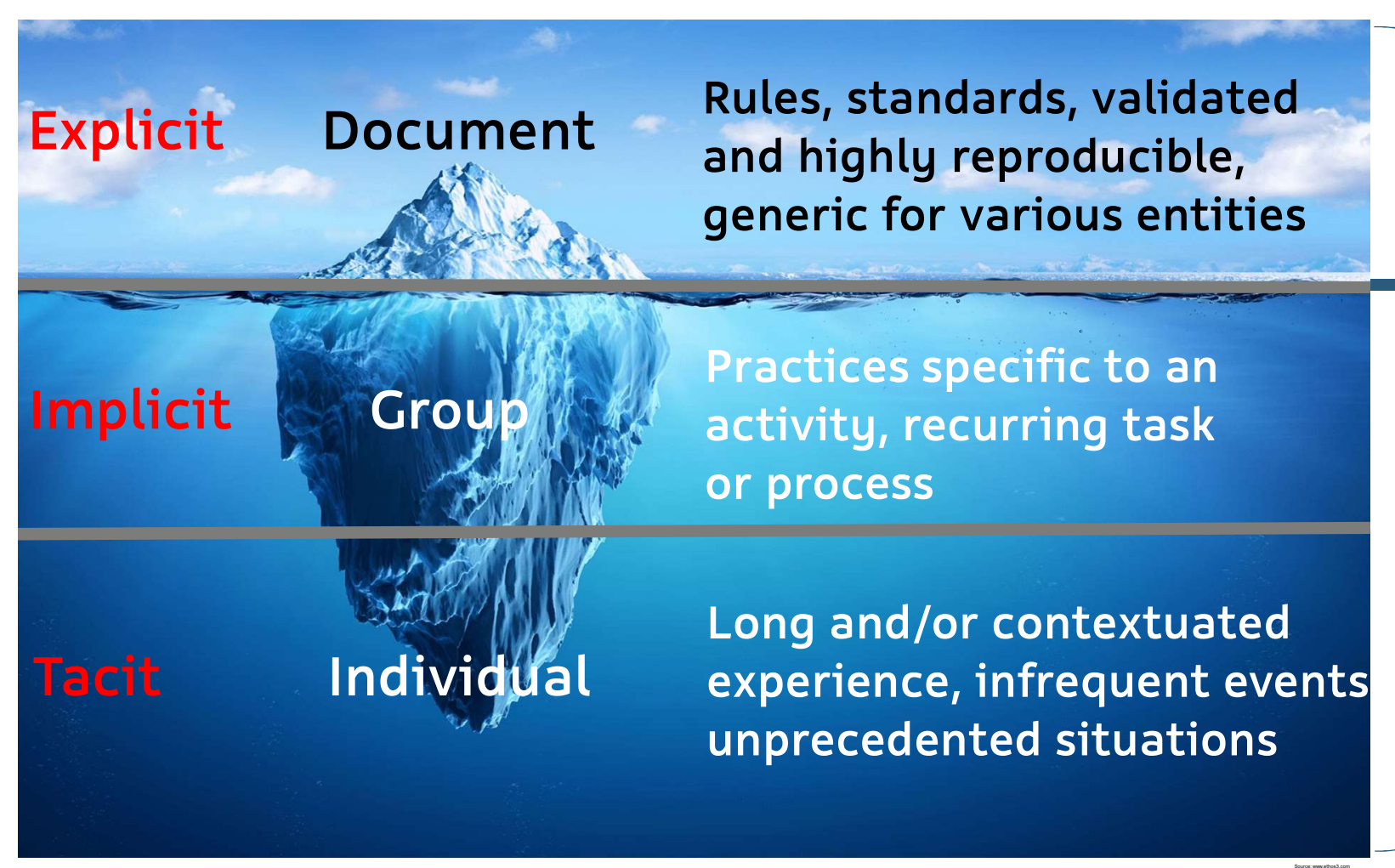

Retrieveable / accessable

"Know how" - individual or group/team related I 


\section{KNOWLEDGE MANAGEMENT IN THE BGE}

- CAPTURE OF IMPLICIT AND TACIT KNOWLEDGE - HOW?

- Social knowledge conversion (Nonaka \& Takeuchi)

- Sharing, capturing

- Observation, imitation, practice

- Apprenticeship, mentoring

- Receiving, application

- Learning-by-doing

- New individual knowledge

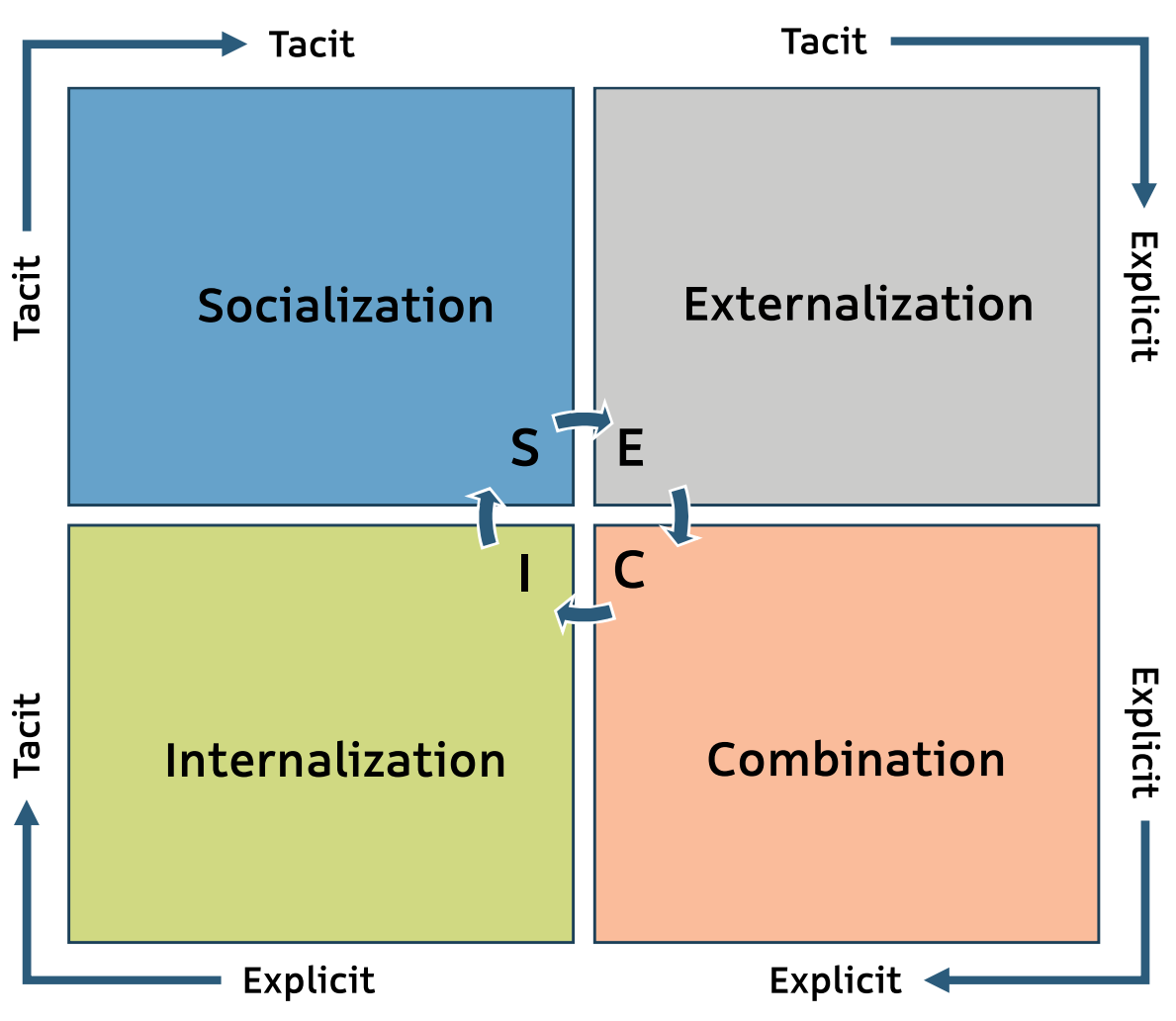

- Processing knowledge

- Articulating, sharing, publishing

- Crystallising, reflecting

- Organising, integrating, conversion

- Merging knowledge and information

- New form of knowledge 


\section{KNOWLEDGE MANAGEMENT IN THE BGE - CHALLENGES AND SOLUTIONS}

- „Hard to catch"/ special challenge

- Voluntariness - without compulsion / support through appreciative leadership culture mandatory

- Positive error culture („lessons learnt"), innovation and employee empowerment as a prerequisite for a living corporate culture 
Saif D

BGE BUNDESGESELLSCHAFt

Interdisciplinary

on the safety of nuclear

disposal practices

\section{THANK YOU VERY MUCH FOR YOU ATTENTION}

